\title{
Multidisciplinary Effort and Integrative Preparedness: A Lesson for the Foreseen Multivariate COVID-19 Pandemic Flare-Up
}

\author{
Ashagrachew Tewabe \\ Yayehrad iD I,2 \\ Ebrahim Abdela Siraj (iD) ${ }^{1,2}$ \\ Dawit Kumilachew Yimenu (iD ${ }^{3}$ \\ Abyou Seyfu Ambaye (iD ${ }^{4}$ \\ Manaye Tamrie Derseh (D) 1,4 \\ Andargachew Almaw Tamene ${ }^{5}$ \\ Tamyalew Getahun Yayeh ${ }^{6}$ \\ 'Department of Pharmaceutics and Social \\ Pharmacy, School of Pharmacy, College of \\ Health Sciences, Addis Ababa University, \\ Addis Ababa, Ethiopia; ${ }^{2}$ Department of \\ Pharmacy, College of Medicine and Health \\ Sciences, Bahir Dar University, Bahir Dar, \\ Ethiopia; ${ }^{3}$ Department of Pharmaceutics and \\ Social Pharmacy, School of Pharmacy, \\ College of Medicine and Health Sciences, \\ University of Gondar, Gondar, Ethiopia; \\ ${ }^{4}$ Department of Pharmaceutics and Social \\ Pharmacy, School of Pharmacy, College of \\ Medicine and Health Sciences, Mizan-Tepi \\ University, Mizan-Aman, Ethiopia; \\ ${ }^{5}$ Department of Medical Laboratory \\ Science, College of Health Sciences, Debre \\ Tabor University, Debre Tabor, Ethiopia; \\ ${ }^{6}$ Addis Alem Primary Hospital, Amhara \\ Regional Health Bureau, Bahir Dar, Ethiopia
}

Correspondence: Ashagrachew Tewabe Yayehrad

Department of Pharmacy, College of

Medicine and Health Sciences, Bahir Dar

University, P.O. Box: 79, Bahir Dar,

Ethiopia

Tel +25I 912960525

Email ashutewabe@gmail.com

\begin{abstract}
It has been a year and a half since the world suffered the horrific COVID-19 pandemic which has still continued becoming a prominent headache for the whole world. Recently, we are facing the second and third wave of multivariate outbreaks with great intensity of transmission which renders huge disaster. Presently, new strains of the virus are emerging that are predicted to be resistant for the current vaccines and other management approaches. It needs collaborative and coordinated role at professional, facility, regional, and global levels to ameliorate the pandemic by monitoring the existing and emerging variants. This review addressed the multidisciplinary roles in patient screening and detection, emergency management, moderate and critical care, vaccination, complication prevention, comorbidity management, psychological therapy, and digital health care. The inevitable roles of academicians, researchers, private health sectors, policy makers, regulatory bodies, and partners are also discussed.
\end{abstract}

Keywords: multidisciplinary approach, COVID-19 management, mental health, digital health care, integrative roles

\section{Introduction}

It has been a year and a half since the globe suffers the horrific coronavirus disease (COVID-19) pandemic. It is still a prominent concern for both developed and developing countries. ${ }^{1}$ Globally, the virus has spread over more than 200 countries; continued to infect more population, caused more deaths; affected the overall health care system; possessed severe economic and psycho-social crisis, and made treatment outcome erratic. ${ }^{2,3}$ A recent report by WHO on July 21, 2021 indicated that there were 192,848,447 confirmed cases, 4,142,769 deaths and 175, 364, 0788 recoveries globally; countries like USA, India, Brazil, Russia and France being in the first line, respectively. ${ }^{4}$ African CDC report, as accessed on 20th July 2021, indicated that a total of $56,103,432$ people have been infected by the virus with $6,306,675$ confirmed cases, 15,882 deaths, and 5,519,658 recoveries. ${ }^{5}$ The disease is caused by a virus called severe acute respiratory syndrome coronavirus-2 (SARSCoV-2) which primarily attacks the respiratory system. ${ }^{6}$ Its transmission is via respiratory droplets from asymptomatic, or symptomatic carriers. After being infected, a person may develop fever, difficulty of breathing, dry cough, and other related symptoms within an average of 5 days. Nonspecific diagnosis such as laboratory abnormalities, lymphopenia, and elevated lactate dehydrogenase as 
well as radiographic imaging can be used to detect and confirm cases. The virus can be diagnosed using a reverse transcription polymerase chain reaction (PCR) testing. Almost $20 \%$ of patients hospitalized with COVID-19 need an intensive care while more than $75 \%$ of them require supplemental oxygen. ${ }^{7}$ Management approaches include managing the acute hypoxic respiratory failure, relieving fever, prescription of re-purposed drugs with antiviral effects, managing comorbidities, and preventing complications. Dexamethasone and remdesivir therapy are reported to improve mortality and time to recovery, respectively. Even though many vaccines are in use and under development today, the primary methods to reduce the spread remain personal protective equipment, physical distancing, and contact tracing. ${ }^{8}$

In general, the need on understanding the COVID-19 pathogenesis, transmission, and treatment is increasing time to time but, the most devastating issue in recent times is the appearance of various multivariate strains which are highly contagious than the original strains and possess significant difficulties in management strategies including vaccination. ${ }^{2,9}$ Newly emerging SARS-CoV-2 variants that are capable of escaping vaccine protection may present a challenge to control the pandemic while the future scenario may be similar to what was observed with vaccines against influenza, where community immunity is seldom expected. ${ }^{10}$ The UK B.1.1.7, the South African B.1.351, and the Brazilian B.1.1.28.1 strains are among the emerging new SARS-CoV-2 variants that displayed various types of mutations ${ }^{11}$ resulting in resistance against most of the currently approved vaccines. ${ }^{12}$ As the second and the third waves of the pandemic are flaring-up with great intensity of transmission, obligatory lockdowns with too many countries may continue. ${ }^{13}$ To respond rapidly and effectively, dozens of COVID-19 vaccine candidates with prioritizing vaccination program; ${ }^{14}$ comprehensive and vital crises management strategies; ${ }^{15}$ multiple training, relevant education, and appropriate communication on comprehensive care to the disadvantaged population, ${ }^{2}$ and a comprehensive multidisciplinary team work are critical needs. ${ }^{16}$ This necessitates a collaborative multidisciplinary response through the monitoring of genetic sequencing of the COVID-19 variants, preparation of more targeted vaccines, and development of more advanced antibody therapies. ${ }^{17}$ In general, to effectively counter the current pandemic, it needs a multi-level, integrated, multidisciplinary approach Figure 1.

\section{Integrative COVID-19 Patient Care in Health Facility Setting}

The main lesson we realized as healthcare professionals during the pandemic is that we need to act together to deliver the best promising outcome for the patients. It has also shown us how mandatory and imperative the multidisciplinary approach is to achieve optimal treatment and rehabilitation goals. ${ }^{18}$ The overall health facility integrative management of COVID-19 is highlighted in Figure 2. ${ }^{19}$ Hospitalized patients should be followed in an integrated multidisciplinary service with a standardized evaluation of clinical symptoms, psychotic status, and total well-being assisted by the test results from a chest X-ray and blood examinations. All the demonstrated cases should then be shared with the multidisciplinary team for evaluation, information updating, and personalized planning. ${ }^{20}$

\section{Triage, Screening and Detection}

The multidisciplinary clinical management approach starts from screening and triage at the primary get way of the health facility. Parallel to screening and triage, there must be immediate initiation of infection prevention and control (IPC). Then, appropriate diagnosis should be done for suspicions. ${ }^{21,22}$ Multidisciplinary patient care involves prompt detection and isolation, appropriate launching and obedience to the IPC, and proper patient care according to their needs. Many professionals and trainees in the medical laboratory field are generously and vigorously fighting the pandemic from the front at public health institute, hospital, and private clinical laboratories throughout the world. ${ }^{23}$ Besides, their role in diagnosis and detection, they have also participated in establishing a global taskforce and an online information guide ${ }^{23,24}$ which provide an updated evidence for screening, detection, and monitoring of hospitalized patients.

There are three critical phases in which laboratories are delivering their role in fighting the pandemic. In the preanalytical phase, clinical laboratories across the globe are doing their best to save lives through appropriate specimen site selection, collection, transport, and storage which are the first and the most important steps for diagnosis of the infection and manage the complications. ${ }^{25}$ They are providing physicians with the needed evidence through laboratory diagnosis based on correct and timely specimen. The possible specimen types include; respiratory tract specimens, saliva, blood, stool, and urine. ${ }^{26}$ In the analytical phase, they provide examination results that will be used in clinical decision making. Inaccurate test results lead to unnecessary treatment, treatment 


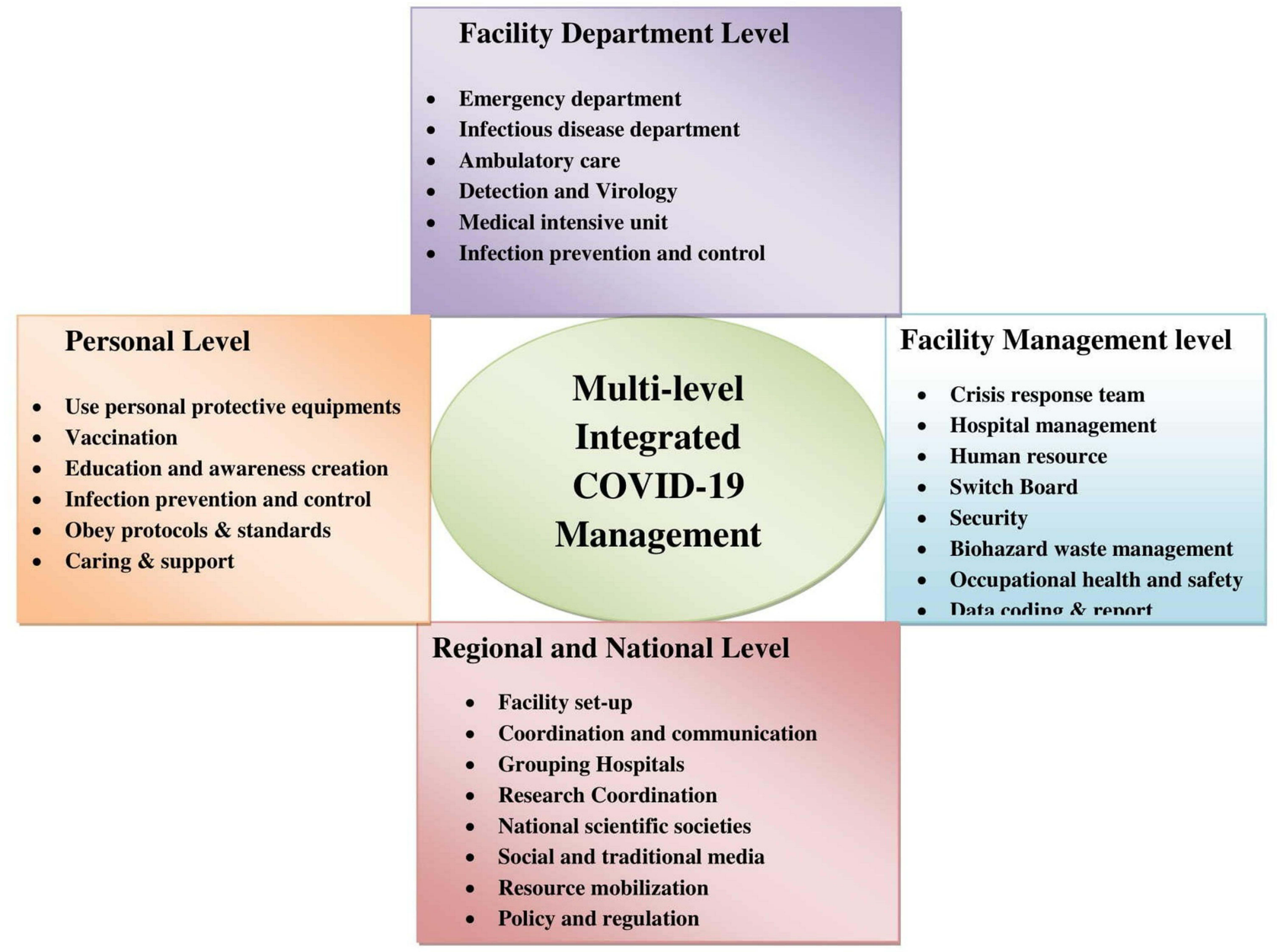

Figure I Multi-level integrative COVID-19 management.

complications, treatment failure, delayed detection, and repetitive testing, and deprived patient outcome ${ }^{27}$ Likewise, they are playing a key role in fast detection of suspicions and monitoring of severe complications. ${ }^{23}$ The diagnostic methods are summarized with Figure $3{ }^{28}$ Finally, in the post-analytical phase, laboratories disseminate the information to frontline care givers for decision-making and the general management strategies of the pandemic. ${ }^{23}$

\section{Emergency Management}

Emergency departments are prioritized as frontline care units across the globe. The pandemic necessitated for reshuffling resources, including personnel, within the systems by cancelling non-emergent procedures. Care givers in this department are very vulnerable as they are in the primary contact to the patients. They have the highest workload during this pandemic, which puts them in greatest risk of distributing the virus to families and friends. ${ }^{29}$ Moreover, they are challenged with shortage of supplies for personal protection and patient case management which challenges during the decision of delivering their service with equity. ${ }^{30}$ Sufficient staffing, facilities, and premises, collectively with well-planned coordination, are necessary to ensure readiness to fight the upcoming unpredicted crisis from the foreseen multi-variant pandemic. ${ }^{31}$ Collaboration with multidisciplinary teams, continuing support from health facility administrative staffs, and optimized patient care flow pathways are mandatory to respond to the highly devastating pandemic crisis. ${ }^{32}$ These issues must get supreme attention in preparing for re-outbreaks or other new pandemics.

\section{Multidisciplinary Infection Management Approach}

Once the diagnosis is confirmed, symptomatic treatments, counseling, and closely monitoring will be followed based on specific patient needs. Patient follow-up must be continued 


\begin{tabular}{|c|}
\hline Symptoms \\
\hline $\begin{array}{l}\quad \text { Incubation 4-14 d } \\
\text { Common: } \\
\text { - Fever }(77 \%-98 \%) \\
\text { - Cough ( }(46 \%-82 \%) \\
\text { - Myalgia or fatigue (11\%-52\%) } \\
\text { - Dyspnea ( } 31 \%) \\
\text { Less common: } \\
\text { - Sore throat, sputum, hemoptysis, itinonthea } \\
\text { - Headache, anosmia, dysgeusia } \\
\text { - Nausea, vorniting, diarnea }\end{array}$ \\
\hline
\end{tabular}

\begin{tabular}{|ll|}
\hline \multicolumn{2}{|c|}{ Common laboratory findings } \\
\hline \\
CBC count: & Inflammation: \\
- Lymphopenia $(63 \%)$ & $: \uparrow$ ESR \\
- Leukocytosis $(24 \%-30 \%)$ & $: \uparrow$ CRP \\
- Leukopenia $(9 \%-25 \%)$ & - $\uparrow$ Ferritin \\
LFTs: & Coagulation: \\
- $\uparrow$ AST,ALT & $: \uparrow$ D-dimer \\
$\uparrow$ LDH & $* \uparrow$ PT \\
& \\
\hline
\end{tabular}

\begin{tabular}{|l|}
\hline \multicolumn{1}{|c|}{ Initial inpatient evaluation } \\
\hline Blood work: \\
- CBC count, differential count \\
- Comprehensive metabolic panel \\
- Creatinine \\
- AST and ALT \\
- CRP \\
- D-dimers \\
- Soluble fibrin monomers complex \\
Influenza A and B. RSV swabs (seasonal) \\
Chest radiography (portable preferred) \\
ECG (selected cases) \\
\end{tabular}

\begin{tabular}{|c|c|}
\hline $\begin{array}{c}\text { Typical HRCT findings } \\
\text { asymptomatic } \\
\text { first week }\end{array}$ & $\begin{array}{l}\text { - Peripheral and patchy (GGOS) } \\
\text { - Frequently bilateral } \\
\text { - Rounded morphology }\end{array}$ \\
$\begin{array}{c}\text { Second } \\
\text { and } \\
\text { third weeks }\end{array}$ & $-\left[\begin{array}{l}\text { - Confluent subpleural and multifocal } \\
\text { GGOs with increased consolidation } \\
\text { - Possible intralobular lines (crazy-paving) } \\
\text { - Lower lobe predominance } \\
\text { - Reverse halo sign or other features of } \\
\text { organizing pneumonia }\end{array}\right.$ \\
\hline
\end{tabular}

\begin{tabular}{|l|}
\hline \multicolumn{1}{|c|}{ Criteria for discharge to home } \\
\hline - Afebrile and hemodynamically stable for $48 \mathrm{~h}$ \\
- Stable respiratory status \\
- Able to perform activities of daily living \\
- Having a place to be safely discharged to \\
- Having the ability to home self-isolate \\
- Home provider who can offer help
\end{tabular}

\section{Home quarantine requirements}

- Quarantine for $7 d$ from hospital discharge or 14 d total since onset of disease (whichever is longer)

- At least $72 \mathrm{~h}$ have passed since resolution of fever without the use of antipyretics

- Improvement in respiratory symptoms

- COVD-19 PCR testing on day 7 of discharge being negative

\section{Remote monitoring}

Clinical symptoms:

- Worsening shortness of breath

- New or worsening cough, productive cough or hemoptysis

- New chest pain or pain with breathing

- Fevers, chills, or sweats

- Vormiting or diartinea

- Lightheadedness

Vital signs:

- Temperature

- Heart rate

- Respiratory rate

- Blood pressure

- Oxygen saturations

Figure 2 Overview of the hospital management of COVID-19 cases.

Notes: Reprinted from: Razonable RR, Pennington KM, Meehan AM, et al. A Collaborative Multidisciplinary Approach to the Management of Coronavirus Disease-2019 in the Hospital Setting. Mayo Clin Proc. 2020;95(7):1467-1481. ${ }^{19} \odot 2020$ Mayo Foundation for Medical Education and Research. With permission from Elsevier.

Abbreviations: ALT, alanine aminotransferase; AST, aspartate aminotransferase; CBC, complete blood cell; CRP, C-reactive protein; ECG, electrocardiography; ESR, erythrocyte sedimentation rate; GGO, ground-glass opacity; HRCT, high-resolution computed tomography; LDH, lactate dehydrogenase; LFT, liver function test; PCR, polymerase chain reaction; RSV, respiratory syncytial virus. 


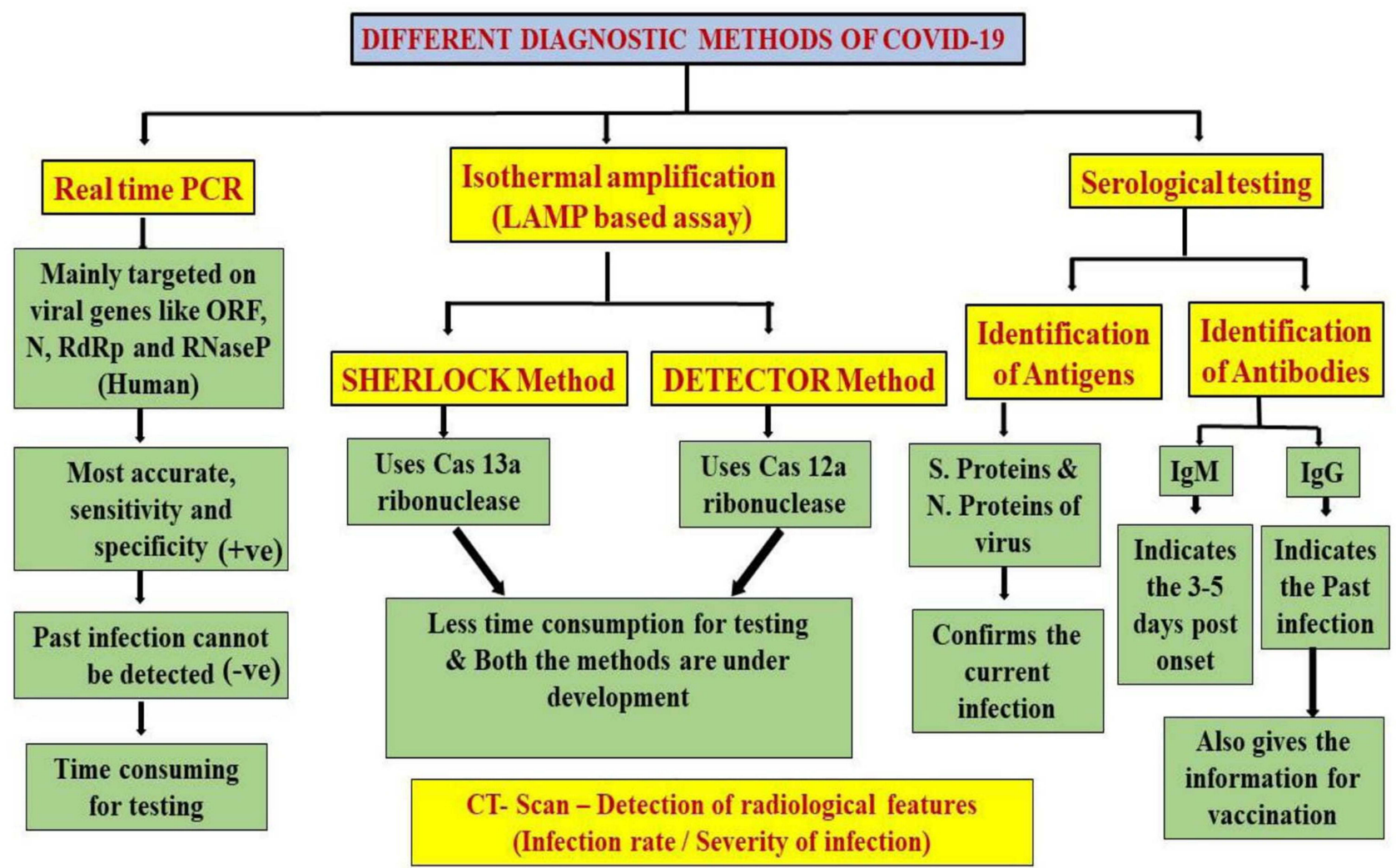

Figure 3 Diagnostic methods of COVID-19 infection.

Notes: Reproduced from: Tomo S, Karli S, Dharmalingam K, Yadav D, Sharma P. The clinical laboratory: A key player in diagnosis and management of COVID-I9. EJIFCC. 2020;3 I (4):326. ${ }^{28}$ Copyright (C) 2020 International Federation of Clinical Chemistry and Laboratory Medicine (IFCC). All rights reserved. Creative Commons Attribution Non-Commercial License (https://creativecommons.org/licenses/by-nc/4.0/legalcode).

to detect signs of clinical deterioration, plan co-management of co-morbid conditions, and tailor the management of critical illness. Prevention of complications (Table 1), need for endotracheal intubation, need for adjunctive therapies, caring for special population such as infants, breast-feeding, pregnancy, and elderly should also take great attention. ${ }^{21}$ The medical care can be best optimized by the collaboration of specialists from various health professionals. Clinical expertise in hospital medicine, pulmonary and critical care medicine, infectious diseases, clinical radiology, cardiology, microbiology, hematology, and primary care are essential for early prevention or treatment of complications. ${ }^{19}$ In addition, physiotherapists, microbiologists, occupational therapists, nurses, dermatologists, anesthesiologists, speech and language pathologists, dieticians, pathologists, drug experts, psychologists, physicians, psychiatrists, neurologists, and social workers are all needed for effective management. Effective communications approaches and routine audits should be outlined to ensure compliance with protocols, standards and guidelines while working in teams. ${ }^{18}$ Multidisciplinary medical community should also be responsible to answer patients' inevitable questions and improve public awareness regarding progresses in drug and vaccine development. ${ }^{22}$ The pharmaceutical department should keep stand-on with the continuous supply of drugs, equipment, antiviral, antimalarials, antibacterial, anticoagulants, immunomodulators, corticosteroids and rescue therapeutic agents. Infection management should be essentially available. ${ }^{33}$ Since pharmaceutical service is now shifting from products-based to services-based and patient-centered, it is now a good opportunity to build an inter- and intradiscipline integration for the fight against the pandemic. They can counsel and educate patients to counteract anxieties from COVID-related misinformation and rumors. Pharmacists should actively perform and ensure a stable supply system of drugs and protective equipment for guaranteeing continuity-of -care especially for vulnerable groups and chronically ill patients. ${ }^{34}$ Pharmacists should also participate in formulating occupational instructions; provide the frontier medical staff adequate and updated medicine information; build up innovative pharmacy services to endorse the rational use of medicines, and develop remote pharmacy care services for enhanced transmission prevention. ${ }^{35}$ Pharmacists are the 
Table I Post-Infection Complication Prevention Measures

\begin{tabular}{|c|c|}
\hline Anticipated Outcome & Interventions \\
\hline $\begin{array}{l}\text { Reduce days of invasive mechanical } \\
\text { ventilation }\end{array}$ & $\begin{array}{l}\text { - Use weaning protocols that include daily assessment readiness to breath spontaneously } \\
\text { - Minimize or intermittent sedation, targeting specific titration endpoints (light sedation unless } \\
\text { contraindicated) with daily interruption of continuous sedative infusions }\end{array}$ \\
\hline Reduced ventilation associated pneumonia & $\begin{array}{l}\text { - Oral intubation is preferable to nasal intubation in adolescent and adults } \\
\text { - Keep patient in semi-recumbent position (head of bead elevation } 30-45^{\circ} \text { ) } \\
\text { - Use a closed sanctioning system, periodically drain and discard condensate intubing } \\
\text { - Use a new ventilator circuit for each patient, once patient is ventilated, change circuit if is soiled } \\
\text { or damaged, but not routinely } \\
\text { - Change heat moisture exchanger when it is malfunctions, when soiled or every 5-7 days }\end{array}$ \\
\hline $\begin{array}{l}\text { Reduced incidence of venous } \\
\text { thromboembolism }\end{array}$ & $\begin{array}{l}\text { - Use pharmacological prophylaxis (low molecular weight heparin (preferred if available)) or } \\
\text { heparin } 5000 \text { units subcutaneously twice daily) in adolescents and adults without } \\
\text { contraindication. For those with contraindications, use mechanical prophylaxis (intermittent } \\
\text { pneumatic compression devices) }\end{array}$ \\
\hline $\begin{array}{l}\text { Reduce incidence catheter related blood } \\
\text { stream infection }\end{array}$ & $\begin{array}{l}\text { - Use a check list with completion verified by a real-time observer as a reminder of each step } \\
\text { needed for sterile insertion and as a daily reminder to remove catheter if no longer needed }\end{array}$ \\
\hline Reduce the incidence of pressure ulcers & - Turn patients every $2 \mathrm{hrs}$ \\
\hline $\begin{array}{l}\text { Reduce the incidence of stress ulcers and } \\
\text { gastrointestinal bleeding }\end{array}$ & $\begin{array}{l}\text { - Give early enteral nutrition (within } 24-48 \text { hrs of admission) } \\
\text { - Administer histamine-2 receptors blockers or proton pump inhibitors in patients with risk factor } \\
\text { for Gl bleeding include mechanical ventilation for } \geq 48 \mathrm{hrs} \text {, coagulopathy, renal replacement } \\
\text { therapy, liver disease, multiple comorbidities, and higher organ failure score }\end{array}$ \\
\hline Reduce incidence & - Actively mobilize the patients early in the course of illness when safe to do so \\
\hline
\end{tabular}

Notes: Adapted from: World Health Organization. Clinical management of severe acute respiratory infection (SARI) when COVID-19 disease is suspected; Interim guidance. Available from: https://www.who.int/docs/default-source/coronaviruse/clinical-management-of-novel-cov.pdf. Accessed July 23, $2021{ }^{21}$ () World Health Organization 2020. Some rights reserved. CC BY-NC-SA 3.0 IGO licence (https://creativecommons.org/licenses/by-nc-sa/3.0/igo/legalcode).

frontline healthcare practitioners, through all the pandemic as they keep on offering direct patient care services. ${ }^{36}$

\section{Integrative Critical Care}

During the pandemic, management of critically ill patients increased the workload in the Intensive Care Unit (ICU) department that has high risk of complications. A pronation team of physiotherapists can help the nursing staff to reduce the work load and rate of complications. ${ }^{37}$ Identification of COVID-related dysphagia needs integrative collaboration from both the intensive and the acute care departments. The inpatient therapeutic team must assess and manage speech and language-related complications, prevent aspiration pneumonia, manage malnutrition and dehydration, and evaluate postural changes. Hence, it needs collaboration between speech and language pathologists, dieticians, respiratory specialists, nursing care, and physiotherapists. ${ }^{38}$ Airway management teams should consist of experienced anesthesiologists to meet the need for accurate and effective intubation. Ventilation management after tracheal intubation, ultrasonography, fast response resuscitation, and preoperative evaluation are benefitable areas from critical care teams incorporating anesthesia experts. ${ }^{39}$ Prompt extension of critical care beds, flexibility from health professionals, rapid establishment of inter-hospital transfer services, integrative care from acute and general medicine, geriatric medicine, and respiratory support units are the lessons learnt from the previous outbreaks. Clinical coding of patient care processes should be applied for supplementary purposes such as payment, clinical audit, planning, and epidemiological studies. Validated data can be documented with integrated coding of patient care processes by senior clinicians and the clinical coding team. ${ }^{32}$ Figure 4 summarizes the integrative multidisciplinary approaches for intensive care of patients. ${ }^{40}$

\section{Consideration of Special Population Groups}

Pregnant women, the elderly, and children need special considerations during the management of the pandemic. Bearing in mind that pregnant women may be asymptomatic 


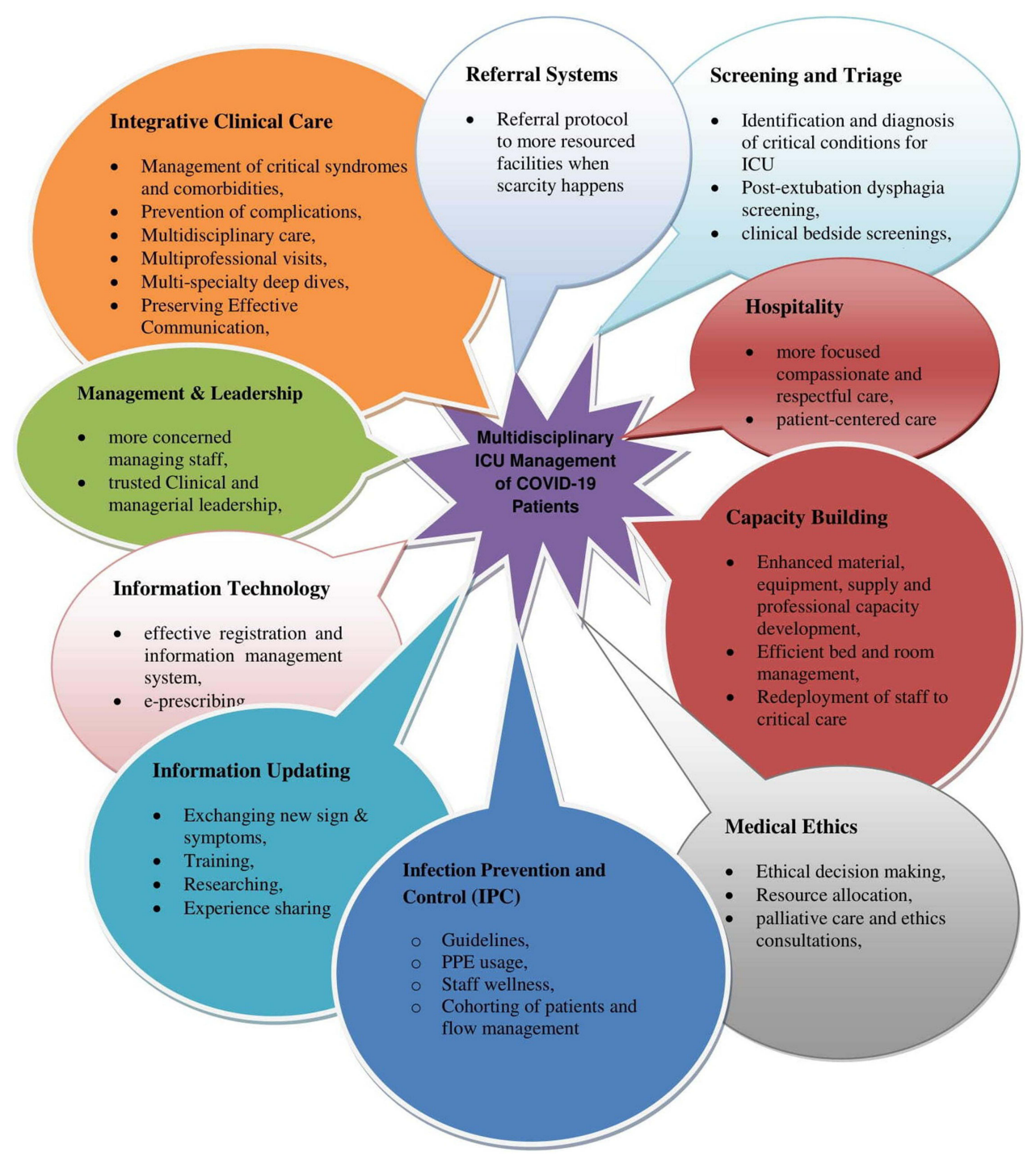

Figure 4 Multidisciplinary approaches for intensive care of COVID-19 patients.

spreaders of COVID-19, it necessitates a woman-centered, multi-disciplinary, esteemed expertise care that consist of obstetric, fetal, neonatal, and mental health care. Pregnant women, who are active or recovered, should be offered with information and advice on protected infant nourishment and prevention techniques to halt the transmission. Additionally, breastfeed mothers should be supported to go for regular antenatal, postpartum, or post abortion care as required. Elders and those with comorbidities should be considered for high-quality healthcare, including intensive care. Beyond that, multidisciplinary cooperation of all health care professionals is highly required to tackle multi-morbidity problems by engaging the care givers and families in the planning, determination, and delivery of the management strategies. $^{21,41}$

\section{Vaccination}

Beginning from the first years of 18th century, pharmacists with other clinical and non-clinical professionals have demonstrated vast important benefit in vaccine discovery, distribution, allocation, and immunization programs. In addition, they integrate, participate-in and lead the delivery of vaccines to health care providers, storage and distribution of vaccines, and preparing anti-toxins. ${ }^{42}$ Reducing deficiencies of vaccines and treatments during the COVID-19 pandemic need multidisciplinary efforts. ${ }^{43}$ Since the goal of vaccine program is to equitably allocate vaccines in transparent way, ${ }^{44}$ pharmacists and the immunization team should play a significant role in advocating the proper utilization of vaccination. ${ }^{42}$ As most COVID 
vaccines need cold chain transport at $2^{\circ} \mathrm{C}$ to $8^{\circ} \mathrm{C}$, countries and health facilities need to have sufficient storage capacity to accommodate any constraints in case of limited cold chain tracks. ${ }^{45}$ In any health related supply chain, transport and storage involves integration of physical products but the forecasting, procurement, information system and order involves the integration of supply chain process. ${ }^{46}$ Pharmacists and other health supply chain professionals are capable of playing important roles in vaccine management like safe supply, administration, and storage. ${ }^{47}$ So vaccination programs need to have systems to quantify the target populations and vaccinate them. ${ }^{48}$ Multidiscipline-based health professionals should interactively act to deliver COVID vaccines at customer level. For wide and rapid coverage of the populations it is important to use the experience of community health facilities from vaccinating influenza. ${ }^{49}$ Due to higher visit rates, patient encounters, and their extended opening hours, community pharmacies are important places to reach broad range of social classes. ${ }^{50}$ In America, most pharmacists provide vaccines without appointment, without waiting, and without visit charges. In addition, they are distributers of vaccines to the clinics and physicians. This makes pharmacists an important professional for mass vaccination. $^{51}$ This can promote the role of pharmacists to improve supply chains and accessibility at the end level.

\section{Occupational Health and Safety/ Environmental Health Workforce}

Environmental health workforces play a great role for promoting the implementation of the IPC measures by mobilizing multidisciplinary skills. They offer an integrated multidisciplinary approach for occupational health and safety assurance by monitoring the situation and planning pro-action measures in the facility and for the community at large. ${ }^{52}$ They have enumerable roles in evaluating environmental health hazards; updating pandemic-related information for community mobilization; forecasting interventions; enacting the developed guidelines; monitoring patient care services; and inventing new potential solutions for the emerging challenges. ${ }^{53}$

\section{Nonclinical Staff Roles in Health Facility}

The non-clinical staffs should be integrated in the fight against the pandemic by facilitating information transfer between the frontline clinicians, patient families, and leaders. The administrative department should manage issues related with hospital beds and turnover, provide and facilitate trainings, and allocate necessarily resources. ${ }^{54}$ They should primarily hold the duty to sure compliance of guidelines and protocols for treatment and prevention of the pandemic. ${ }^{55}$ Effective leadership creates safety and wellbeing to staff members, ensure continuous availability of resources, and create an atmosphere of team-work. ${ }^{56}$ Non-clinical areas may possibly be highrisk for spread involving healthcare workers by frequently ignoring the infection prevention and control protocols. ${ }^{57}$ Therefore, staff safety encouragement and monitoring is important to ascertain an effective prevention of risk burnout. A multidisciplinary effort from clinical and nonclinical decision makers is needed for establishing an even way of communicating updated expertise information for the briskly changing conditions during the pandemic. In addition, flexible strategies accompanied by electronic based data systems should be implemented for identifying patient-specific data, managing co-infections, and forecasting further needs on combating the pandemic crisis. ${ }^{32}$

\section{Experience from Patient Care Models and Protocols}

Various investigators, nations and organizations have been developing their own COVID-19 management models and protocols. New York City hospitals developed multidisciplinary protocols for focused critical care and prevention of post-infection complications. Multidisciplinary approaches for efficient ICU timing, minimizing staff exposure, standardization of critical care, expanding operating rooms, efficient bed management are all addressed with the protocol. The protocol outline provides a practical guide to encounter the COVID-19 management challenges with local solutions through interdisciplinary collaboration. The identified challenges in the guideline and the recommended local solutions are presented in Table 2. ${ }^{58}$ Dennerlein et al developed a multidisciplinary model of health care delivery and social health maintenance with six vital functional principles. The principles are (i) concentrating on IPC implementation and psychosocial support; (ii) employing participatory approaches comprising workers; (iii) increasing system efficiencies by comprehensive and collaborative efforts; (iv) establishing a supportive communication strategy; (v) complying with ethical and legal standards; and (vi) guiding and evaluation based on documented data. ${ }^{56}$ 
Table 2 Solutions to Encountered Challenges During COVID-19 Management

\begin{tabular}{|c|c|}
\hline Challenges & Local Solution \\
\hline Infection control & Define aerosolizing procedures; use guidelines to define appropriate PPE \\
\hline \multicolumn{2}{|l|}{ Clinical Challenges } \\
\hline Decision to intubate & Evolving; determined by clinical judgment with no predefined criteria \\
\hline Airway management & $\begin{array}{l}\text { Intubation by RSI by most experienced operator; periintubation team to assist in gathering PPE and } \\
\text { medications and to assist in transport }\end{array}$ \\
\hline $\begin{array}{l}\text { Engagement of infectious disease } \\
\text { team }\end{array}$ & Universally consulted to assist with therapies and entry into clinical trials \\
\hline Extracorporeal organ support & Patients evaluated by a multidisciplinary team on a case-by-case basis \\
\hline Cardiac arrests & Policy limits the number of responders and promotes enhanced PPE \\
\hline Standardization & Frequent conferences, daily e-mail updates, and shared files \\
\hline $\begin{array}{l}\text { Approaches to efficient use of time } \\
\text { in the ICU }\end{array}$ & Create procedure team, proning team, and tracheostomy team; display results and \\
\hline Minimizing exposure & Bundle care, trial intravenous pumps, and ventilator monitors outside of the patient \\
\hline Education & Frequent, multidisciplinary conferences, and journal clubs \\
\hline Communication with families & Daily calls to a patient surrogate; involvement of palliative care \\
\hline ICU surge capacity & Increase COVID-19 capacity in multiple units simultaneously to expand expertise \\
\hline Expansion to operating rooms & $\begin{array}{l}\text { Multidisciplinary approach to understand differences between critical care ventilators and anesthesia } \\
\text { machines }\end{array}$ \\
\hline Efficient bed management & Appoint a clinical bed manager \\
\hline \multicolumn{2}{|l|}{ Staffing } \\
\hline Physician staffing & $\begin{array}{l}\text { Create a model with ideal ratios of critical care physicians to ICU patients; use critical care experts from all } \\
\text { backgrounds }\end{array}$ \\
\hline Research faculty & Redeployed to clinical service if not doing COVID-19-specific research \\
\hline Nursing and respiratory therapy & Rapid training in ICU skills; expedited recredentialing, education on newly introduced ventilators \\
\hline Nonclinical staff & Acknowledge support from nonclinical staff \\
\hline Ethical dilemmas & Use institutional ethics committees, with guidance from local laws, to approach each ethical decision \\
\hline Staff wellness & Partner with mental health professionals for staff \\
\hline
\end{tabular}

Notes: Reproduced from: Griffin KM, Karas MG, Ivascu NS, Lief L. Hospital Preparedness for COVID-19: A Practical Guide from a Critical Care Perspective. Am J Respir Crit Care Med. 2020;20I (I I):I337-1344. ${ }^{58}$ Creative Commons Attribution Non-Commercial No Derivatives License 4.0 (https://creativecommons.org/licenses/by-nc-nd/4.0/legalcode). Abbreviations: COVID-19, coronavirus disease; PPE, personal protective equipment; RSI, rapid sequence induction.

Aliberti et al reported an integrative model that possessed the multidisciplinary strategies for the management of hospitalized patients as well as for infection control as stated in Table $3 .^{59}$ The model focused on identifying manageable conditions of the infection, detecting health deteriorations early, and managing their comorbidities and complications in a better way. ${ }^{59}$ Haleeqa et al developed a protocol with eight strategies for multidisciplinary supportive care for optimizing management outcomes. The eight strategies are daily multidisciplinary meetings, co-infection screening and management, encouraging early and frequent prone positioning, avoiding hypoxia, anticoagulation, encouraging early mobilization and rehabilitation, evidence-based drug prescribing habit, and providing psychological support. These recommendations support clinician decisions for enhanced patient care outcomes. ${ }^{60}$ 
Table 3 Health Professionals for Multidisciplinary Approach

\begin{tabular}{|c|c|}
\hline Respiratory Physicians & $\begin{array}{l}\text { - Initial evaluation of the patient } \\
\text { - Choice of respiratory support } \\
\text { - Evaluation and placement of central vein catheter and or arterial catheter } \\
\text { - Identify signs of sepsis and multi organ failure } \\
\text { - Setting of sedative therapy, nutritional therapy and antithrombotic prophylaxis, hydration, antiviral and antibiotic } \\
\text { therapy }\end{array}$ \\
\hline Fellow & $\begin{array}{l}\text { - Initial evaluation of the patient } \\
\text { - Placement of arterial catheter } \\
\text { - Blood and microbial tests request } \\
\text { - Arterial blood gas test } \\
\text { - Pneumonia follow up with lung ultrasound }\end{array}$ \\
\hline Nurse & $\begin{array}{l}\text { - Preparation of medical device to support respiratory insufficiencies } \\
\text { - ECG } \\
\text { - Placement of venous catheter } \\
\text { - Placement of bladder catheter } \\
\text { - Collection of vital parameters } \\
\text { - Therapies administration }\end{array}$ \\
\hline $\begin{array}{l}\text { Respiratory } \\
\text { physiotherapist }\end{array}$ & $\begin{array}{l}\text { - Evaluation with respiratory physician of ventilation/oxygen support } \\
\text { - Early mobilization }\end{array}$ \\
\hline Cardiologist & $\begin{array}{l}\text { - Evaluation and placement of the central venous catheter and /or arterial catheter } \\
\text { - Identification and management of cardiac complication } \\
\text { - Anti-hypertensive therapy } \\
\text { - Inotropic support }\end{array}$ \\
\hline $\begin{array}{l}\text { Infectious disease } \\
\text { specialist }\end{array}$ & $\begin{array}{l}\text { - Identification of patient candidate to anti- viral or anti-inflammatory } \\
\text { - Choice of antiviral drugs } \\
\text { - Choice of antibiotic therapy } \\
\text { - Identification and treatment of sepsis } \\
\text { - Super-infection identification and management }\end{array}$ \\
\hline Rheumatologist & $\begin{array}{l}\text { - Identification of patient candidate to the anti inflammatory and specific anti cytokine treatment } \\
\text { - Definition of tailored anti inflammatory strategy according to the patient characteristics }\end{array}$ \\
\hline Intensivist & $\begin{array}{l}\text { - Multi disciplinary discussion to early identify patient candidates to intensive care management } \\
\text { - DNI/DNR status }\end{array}$ \\
\hline
\end{tabular}

Notes: Reproduced from: Aliberti S, Amati F, Pappalettera M et al. COVID-19 multidisciplinary high dependency unit: the Milan model. Respiratory Research. 2020;21:260. ${ }^{59}$ Creative Commons Attribution 4.0 International License (https://creativecommons.org/licenses/by/4.0/legalcode).

Abbreviations: DNI/DNR, do not resuscitate or intubate; ECG, electrocardigram.

Psychosocial support, collaboration, and networking are as much important as infection control during the pandemic and disaster management. In Korea, the multidisciplinary team of mental health was established immediately and integrated successfully with the clinical and non-clinical teams. $^{61}$

Italians developed a model for guiding the primary care set-up of managing the infection with a standardized approach of the preventive measures and the treatment approaches. It also provided insights from different specialties that may help in guiding

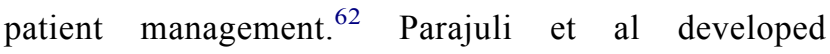
a multidisciplinary individual and regional risk assessment and communication tool to effectively prevent and manage re-infections, comorbid severities, and post-COVID complications at individual, regional, and national levels. The tool is suggested to be easily adaptable across the globe. ${ }^{63}$ Balkhair et al reported an innovative "virtual interdisciplinary COVID-19 team" approach where a multidisciplinary but 
interconnected team from clinical, diagnostic, and administrative departments serves COVID-19 patients with the " $4 \mathrm{~S}$ " theory (staff, stuff, structure, and systems) under one command. ${ }^{64}$

\section{COVID-Related Multidisciplinary Supportive Care Post-Discharge Follow-Up, Mental Health Service, and Psychosocial Support}

Since investigations has not still brought with a verified effective antiviral therapy, supportive care has remained as the standard patient care and management approach. The medical and non-medical supportive care for the patients must be continued after the patient is discharged. These practices can reduce hospital stays, prevent post-discharge complications, and eliminate probability of re-admissions. ${ }^{19,65}$ Experiences suggested that substantial physical and mental disorders could continue after recovery and discharge. ${ }^{20}$ Infection pathogenesis, fear from observed deaths, information congestion, medication use, low-economy, resource constraints, leadership approaches, preexisting psychiatric disorders, substance abuse, and social restrictions can be factors for pandemicrelated mental disorders. Despite these concerns, mental health services are insufficiently prioritized in clinical settings. ${ }^{29}$ The increased risk of mental, social, and psychological disorders should be addressed by expanding multidisciplinary health care practice. ${ }^{66}$ Psychological first aid can be delivered by trained teachers, religious leaders, and elders or by health care professionals. $^{29}$

\section{Multidisciplinary Care for Comorbidity and Post-Infection Complications}

The current COVID-19 pandemic affects most of the body organs. Infection may sometimes start by gastrointestinal manifestation preceding respiratory symptoms ${ }^{67}$ In addition, there may be involvement of cardiovascular and renal systems, ${ }^{68,69}$ the nervous system, ${ }^{70}$ ocular $^{71}$ and psychiatric ${ }^{72}$ disorders. These long-term multi-organ complications are summarized in Table $4 .{ }^{73}$ Evidences on post-COVID conditions demonstrated that $30-70 \%$ of infected people exhibit mild to disabling long-term symptoms. ${ }^{74}$ Understanding the multidimensional nature of the pandemic, assessment, treatment, and follow-up of hospitalized and discharged patients with expertise knowledge from multi-specialties. ${ }^{31}$ This will enhance patient care delivery for post-complications and comorbidities, especially in cases of chronic diseases.
Table 4 Post-COVID Complications by Organ Systems

\begin{tabular}{|c|c|}
\hline Organ System & Post-Acute Covid-19 Symptoms \\
\hline General Assessment & $\begin{array}{l}\text { - Asthenia } \\
\text { - Muscle weakness } \\
\text { - Diffuse pain } \\
\text { - Myalgia, joint pain } \\
\text { - Weight loss } \\
\text { - Deterioration of the quality of life }\end{array}$ \\
\hline Respiratory & $\begin{array}{l}\text { - Dyspnoea } \\
\text { - Cough } \\
\text { - Radiologic sequelae } \\
\text { - Functional impairment } \\
\text { - Dysfunctional breathing } \\
\text { - Chronic oxygen dependence }\end{array}$ \\
\hline Psychiatric and neurological & $\begin{array}{l}\text { - Post-traumatic stress } \\
\text { - Depression } \\
\text { - Anxiety } \\
\text { - Insomnia } \\
\text { - Headache } \\
\text { - Cognitive impairment/brain fog/ } \\
\text { - Dysautonomia }\end{array}$ \\
\hline Cardiovascular & $\begin{array}{l}\text { - Chest pain } \\
\text { - Palpitation } \\
\text { - Autonomic Dysfunction } \\
\text { - Myocardial fibrosis } \\
\text { - Venous thromboembolic disease }\end{array}$ \\
\hline Renal & - Persistent impaired renal function \\
\hline Ear-nose-throat & $\begin{array}{l}\text { - Persistent anosmia or parosmia } \\
\text { - Persistent ageusia }\end{array}$ \\
\hline Endocrine & $\begin{array}{l}\text { - Thyroiditis } \\
\text { - Onset or worsening of diabetes }\end{array}$ \\
\hline Dermatological & $\begin{array}{l}\text { - Hair loss } \\
\text { - Skin rash }\end{array}$ \\
\hline Gastrointestinal & - Diarrhea \\
\hline
\end{tabular}

Notes: Reproduced from: Montani D, Savale L, Beurnier A et al. Multidisciplinary approach for post-acute COVID-19 syndrome: time to break down the walls. Eur

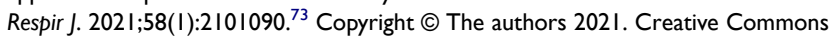
Attribution Non-Commercial Licence 4.0 (https://creativecommons.org/licenses/bync/4.0/legalcode).

A significant joint effort, multidisciplinary teamwork, and common vision are important for delivering the suitable care for cancer patients during this pandemic. ${ }^{75,76}$ The scenario will be more complicated for lung cancer cases. In management of such patients, a distinct, reliable, and evidence-based public health information management system is basically required. Staff and healthcare delivery systems also must ensure that there is safe physical route whilst providing support and empathy for patients. As with many aspects of the pandemic, lung 
cancer multidisciplinary teams should pull together to optimize patient outcomes. ${ }^{77}$ A multidisciplinary team from pulmonologists, internists, and all sub-specialties must work on identification of deteriorations; testing co-infections; promoting evidence-based prescribing; encouraging early mobilization and rehabilitation, and providing psychological support. ${ }^{60}$ Various functional foods, phytochemicals, herbal products, and vitamins showed beneficial effects in strengthening the immune system. So, biologists, chemists, nutritionists, and traditional health practitioners are also not far from the integrative approach. $^{78}$

\section{Multidisciplinary Digital Health Care}

Digital health care systems offer an innovative remote management approach to better manage the pandemic. This can be applied for rapidly sharing targeted information, training the health workforce, delivering home patient cares, facilitating peer-to-peer communication, or implementing surveys. ${ }^{41}$ They can further be used in psychotherapy and mental health services. ${ }^{79}$ Both health and non-health professionals can use the social media communications to upgrade the global fight against the pandemics by balancing the public activation and the associated panic. Public health officials can share timely information; provide guidance, and increase public health awareness, so that it could ease public anxiety and improve health outcomes. ${ }^{80}$ Smartphone applications can be applied to follow vital signs remotely. ${ }^{81}$ Telemedicine is a golden alternative for reducing patient exposures to health professionals and other people as there is conspiracy on the supply of PPEs, medical staff, and hospital beds. ${ }^{79,82}$ The psychology and psychiatry team can offer tele-health consultations for patient-to-family communication. ${ }^{60}$

\section{Integrated Care from Private (Community) Health Sectors}

Private health sectors like community pharmacy, whole sales, hospitals, clinics, diagnostic centers, and health consultants should be mobilized to overturn the pandemic by developing and applying context-appropriate IPC procedures. They should play their role in decreasing pandemic-related morbidity and mortality by offering suitable patient care, guaranteeing service continuousness, and ensuring protection of their staffs and the community they serve. ${ }^{83}$ Partnership and collaboration, community protection, agile and adaptive community services, and sustainable care are needed from the private sector at every level of fighting the pandemic. ${ }^{84}$ They should also assist the vaccination programs by participating in planning, coordination, community mobilization, target identification, vaccine delivery, and follow-up. ${ }^{85}$ Community pharmacists have reduced the load on the healthcare system by turning away the influx of patients from hospitals. ${ }^{36}$ Community pharmacists have also taken part in a range of responsibilities during the pandemic, such as providing medications to the patients, advising the patient on tele-health services, monitoring patients who take regular medications for chronic comorbidity, providing advice on minor conditions, elucidating misunderstandings about COVID-19 treatments, and supporting screening to COVID-19. ${ }^{86}$

\section{Role of Academicians, Researchers, and Regulatory Bodies Multidisciplinary Academic Perspectives}

The academic system was extensively affected by the pandemic as academic and research activities, face-toface conferences, and conventions were disrupted. The pandemic calls the academics for inter- and intradisciplinary collaborations and integrative preparedness to fight and prevent its crisis. Social supports, engineering technologies, healthcare deliveries, research and developments, leadership and financing, art and philosophy are struggling to integrate their work with a common vision. ${ }^{87}$ Multidisciplinary and integrated academic research, innovation, monitoring, and enhancement of the current modalities to discourse all the physical, mental, social, and economic rehabilitation needs associated with the pandemic crisis are vital. ${ }^{88}$ In the first days of the pandemic, important academic consideration had been taken for vaccine progress and equitable distribution across the global population. ${ }^{89}$ Academicians also have pronounced role in delivering psychosocial support for the patients and frontline health workers, continuously updating the clinicians, and facilitating technology-based expert discussions with respective and multidisciplinary departments. ${ }^{90}$

\section{Integrated Regulatory Response}

The COVID-19 pandemic has prompted an urgent need for worldwide and local cooperation and cooperative activities in all facets of the response, owing to its massive humanitarian disaster around the world. The current burden of the COVID-19 outbreak in many developing nations is exceeding the capability of local health-care systems, 
putting it in jeopardy. ${ }^{91}$ The integrative approach between many stakeholders, and multi-sector coordination and team work is quite important in strengthening response strategies and protecting human lives. Given the current scale of the pandemic and the raise of new strains (including the new delta virus), every country should extend its preparedness and response operations, through strengthening its screening, diagnosis and treatment of cases; contact tracing, awareness creation in the community, creating traveler protocols and infection prevention in health facilities. ${ }^{92}$

Similarly, countries should also give emphasis to accelerating research, and fair distribution of vaccinations. It can be an important factor in making universally agreed protocols that can improve integrative research through multidisciplinary team work. ${ }^{92}$ It is important to have networked organizational entities, and multi-sectorial initiatives for up-to-date information sharing and to build a collaborative integration between science, policy and politics. ${ }^{93,94}$

\section{Coordination, Planning, and Monitoring}

The COVID-19 pandemic, with its highly dynamic trajectory and huge interconnected factors, is difficult for a single stakeholder alone to respond the pandemic. Every stakeholder is needed to work cooperatively in a scientific manner to generate a valid and up to date information about the epidemiology of the pandemic and assessing the impact of different interventions. The response to the pandemic will be very weak if there are no such linked activities between stakeholders. ${ }^{94}$

At the beginning of the current pandemic, the initial policy responses of many countries were not well coordinated internationally which clearly implies poor regulatory tie-up. A number of factors were considered responsible for the observed practice including difference in the context of countries and disease stages. In some cases, inadequate attention for the international environment may also be responsible for the differences observed in regulatory approaches of many countries, which in turn resulted in ineffective policy. Effective regulatory cooperation in key areas requires sharing of scientific ideas, which enables the advancement and continuous supply of diagnostic kits, therapeutics and vaccines. ${ }^{95}$

\section{Guidance, Surveillance, and Rapid Response}

Work load and tension to achieve social health needs is expected from decision makers in the time of global emergencies like COVID 19. For fast and timely response to the pandemic by decision makers, it is necessary to establish fast response task force which can potentially avail quality information for decision makers. These task forces should be well educated and should have access to different equipment for epidemic/pandemic investigation with treatments when necessary. This might need the distribution of different materials and establishment of surveillance systems. ${ }^{92,96}$

Policy makers together with authorities can prepare different materials and approve regulatory and market issues of vaccines and pharmacovigilance in support of creating a research atmosphere. ${ }^{92,97}$ These authorities, with the help of partner organizations upon a call, can help the effort in different ways. Among these are designation of patient care referral facilities, re-mapping and reorganizing the referral links and health facilities. Global and local partners could also support national health systems by information dissemination, training and refreshing professionals on COVID-19 specific protocol which will strengthen their current potential readiness for future outbreaks. ${ }^{92}$

\section{Risk Communication and Community Engagement}

Timely risk communication between countries and the people is an important intervention in public health. For quick update about the pandemic, there should be an active communication network including the mainstream and social media. The gaps in the health care system can be filled by community health workers by promoting preventive measures in active fight of the pandemic. ${ }^{98,99}$

\section{Multidisciplinary Research}

In case of pandemics the scientific irregularity of information makes decision difficult. Thus, transparent interconnected networks between stakeholders are very important ${ }^{94}$ World learned innovation and proactive measures from COVID-19. The proactive diagnostic and treatment approaches are proven to be preferable than the retrospective approach to definitely tackle the pandemic outbreaks by promoting research and development activities. ${ }^{100}$ To resolve conflicts occurred between decision makers and researchers, it is very critical to include researchers in policy making process. Standardized research protocol can help researchers to have an access to different funders and prioritizing researches. This can help researchers in the world in sharing of data and specimens during COVID 19 or future pandemics. The most 
strong and important methods will be used if standardization is done. ${ }^{92}$

The involvement of complementary disciplines in research is one way to improve public health care. Every profession can play a pivotal role in achieving this goal. For example, pharmacists should conduct clinical trials and investigations for effective drug and vaccine development; ${ }^{101}$ future pandemics can be forecasted by epidemiologists and mathematicians; ${ }^{102}$ personal protective equipment can be designed by engineers, chemists and physicists for preventing COVID 19 dissemination; ${ }^{90}$ the nature of the pathogen host interaction can be studied by biologists. ${ }^{103,104}$

\section{Conclusion}

To conclude, since COVID-19 occurred suddenly as a global pandemic, it is not easy to tackle its transmission and influence on the health and economy of different countries by standing as a single entity. From our review of literatures, we have learnt that the world clearly understands the necessity of a multidisciplinary effort in the fight against this pandemic. A part from multidisciplinary efforts by professionals, information sharing and risk sharing by different countries or stakeholders had become very important in case of pandemics like COVID-19. Leaders of countries should build or strengthen multi-disciplinary task forces for the available COVID 19 and future pandemics. The team can be built from academicians, information technology professionals, health professionals as well as individuals from paramedics. The involvement can be from epidemic investigation to rehabilitation activities. Preparing isolation rooms, identification of different variants, vaccine development, production of equipment for infection prevention, production and supply of medicines for supportive care are some of the key roles which can be covered by a multi professional effort. Over all, without any multidisciplinary activities, no strong country or health care system can resist health problems and pandemics like COVID-19.

\section{Abbreviations}

CDC, Centers for Disease Control \& Prevention; COVID-19, Coronavirus Disease-2019; ICU, Intensive Care Unit; IPC, Infection Prevention and Control; PCR, Polymerase Chain Reaction; SARS-CoV-2, Severe Acute Respiratory Syndrome-Coronavirus-2; WHO, World Health Organization.

\section{Author Contributions}

All authors contributed to data analysis, drafting or revising the article, have agreed on the journal to which the article was submitted, gave final approval of the version to be published, and agreed to be accountable for all aspects of the work.

\section{Funding}

No funding was available.

\section{Disclosure}

The authors report no conflicts of interest in this work.

\section{References}

1. Lone SA, Ahmad A. COVID-19 pandemic-an African perspective. Emerg Microbes Infect. 2020;9(1):1300-1308. doi:10.1080/ 22221751.2020.1775132

2. Ramaiah P, Tayyib NA, Alsolami FJ, Lindsay GM, Asfour HI. Health professionals dynamic role amid covid-19: nursing perspectives. J Pharm Res Int. 2020:93-100. doi:10.9734/jpri/ 2020/v32i2230776

3. Kumar V, Doshi KU, Khan WH, Rathore AS. COVID-19 pandemic: mechanism, diagnosis, and treatment. $J$ Chem Technol Biotechnol. 2021;96(2):299-308. doi:10.1002/jctb.6641

4. World Heath Organization. Weekly epidemiological update on COVID-19-27 July 2021. Available from: https://www.who.int/ publications/m/item/weekly-epidemiological-update-on-covid-1927-july-2021. Accessed September 9, 2021

5. CDC. Latest updates on the COVID-19 crisis from Africa CDC; 2021. Available from: https://africacdc.org/covid-19/. Accessed July 26, 2021.

6. Shinde V, Bhikha S, Hoosain Z, et al. Efficacy of NVX-CoV2373 Covid-19 vaccine against the B. 1.351 variant. $N$ Engl $J$ Med. 2021;384(20):1899-1909. doi:10.1056/NEJMoa2103055

7. Zhai P, Ding Y, Wu X, Long J, Zhong Y, Li Y. The epidemiology, diagnosis and treatment of COVID-19. Int J Antimicrob Agents. 2020;55(5):105955. doi:10.1016/j.jjantimicag.2020.105955

8. Wiersinga WJ, Rhodes A, Cheng AC, Peacock SJ, Prescott HC. Pathophysiology, transmission, diagnosis, and treatment of coronavirus disease 2019 (COVID-19): a review. JAMA. 2020;324 (8):782-793. doi:10.1001/jama.2020.12839

9. van Oosterhout C, Hall N, Ly H, Tyler KM. COVID-19 evolution during the pandemic-Implications of new SARS-CoV-2 variants on disease control and public health policies. Virulence. 2021;12 (1):507-508. doi:10.1080/21505594.2021.1877066

10. Johansen K, Nohynek H. No country or continent is on its own in the ongoing COVID-19 pandemic. Eurosurveillance. 2021;26 (17):2100430. doi:10.2807/1560-7917.ES.2021.26.17.2100430

11. Stiasny K. Profiles of current COVID-19 vaccines. Wien Klin Wochenschr. 2021;133(7-8):271-283. doi:10.1007/s00508-02101835-w

12. Kumar A, Dowling WE, Román RG. et al. Status report on COVID-19 vaccines development. Curr Infect Dis Rep. 2021;23 (6):1-12. doi:10.1007/s11908-021-00752-3

13. Hossain MK, Hassanzadeganroudsari M, Apostolopoulos V. The emergence of new strains of SARS-CoV-2. What does it mean for COVID-19 vaccines? Expert Rev Vaccines. 2021:1-4. doi:10.1080/14760584.2021.1915140

14. He Q, Mao Q, Zhang J, et al. COVID-19 Vaccines: current understanding on immunogenicity, safety and further considerations. Front Immunol. 2021;12:669339. doi:10.3389/ fimmu.2021.669339 
15. Sapkal GN, Yadav PD, Ella R, et al. Inactivated COVID-19 vaccine BBV152/COVAXIN effectively neutralizes recently emerged B. 1.1. 7 variant of SARS-CoV-2. J Travel Med. 2021;28(4):taab051. doi:10.1093/jtm/taab051

16. Parkin A, Davison J, Tarrant R, et al. A multidisciplinary NHS COVID-19 service to manage post-COVID-19 syndrome in the community. J Prim Care Community Health 2021;12:21501327211010994. doi:10.1177/21501327211010994

17. Pageaud S, Ponthus N, Gauchon R, et al. Adapting French COVID-19 vaccination campaign duration to variant dissemination. medRxiv. 2021. doi:10.1101/2021.03.17.21253739

18. Physiopidea. The Multidisciplinary Team and COVID-19; 2021. Available from: https://www.physio-pedia.com/The Multidisciplinary Team and COVID-19. Accessed July 23, 2021.

19. Razonable RR, Pennington KM, Meehan AM, et al. A collaborative multidisciplinary approach to the management of Coronavirus disease-2019 in the hospital setting. Mayo Clin Proc. 2020;95(7):1467-1481. doi:10.1016/j.mayocp.2020.05.010

20. O'Brien H, Tracey MJ, Ottewill C, et al. An integrated multidisciplinary model of COVID-19 recovery care. Ir J Med Sci. 2020;190(2):1971. doi:10.1007/s11845-020-02354-9.

21. World Health Organization. Clinical management of severe acute respiratory infection (SARI) when COVID-19 disease is suspected. Interim guidance; March 13, 2020. Available from: https://www.who.int/docs/default-source/coronaviruse/clinicalmanagement-of-novel-cov.pdf. Accessed July 23, 2021.

22. Hahn SM. The critical role of health care professionals during the COVID-19 pandemic; August 10, 2020. Speech by FDA Officials. Available from: https://www.fda.gov/news-events /speeches-fda-officials/critical-role-health-care-professionalsduring-covid-19-pandemic-08102020. Accessed July 23, 2021.

23. Adeli K. Critical role of laboratory medicine in the global response to the covid-19 pandemic. Clin Chem Lab Med. 2020;58(7):1019-1020. doi:10.1515/cclm-2020-0742

24. Kavsak PA, De Wit K, Worster A. Emerging key laboratory tests for patients with Covid-19. Clin Biochem. 2020;81:13. doi:10.1016/j.clinbiochem.2020.04.009

25. Sahajpal NS, Njau A, Mondal AK, et al. Role of clinical laboratories in response to the covid-19 pandemic. Future Sci. 2020. doi:10.4155/fmc-2020-0129

26. Wang W, Xu Y, Gao R, et al. Detection of sars-cov-2 in different types of clinical specimens. JAMA. 2020;323(18):1843-1844.

27. World Health Organization. Laboratory Quality Management System: Handbook. World Health Organization; 2011.

28. Tomo S, Karli S, Dharmalingam K, Yadav D, Sharma P. The clinical laboratory: a key player in diagnosis and management of covid-19. EJIFCC. 2020;31(4):326.

29. Hinchman A, Ali D, Goodwin BW, Gillie M, Boudreaux J, Laborde Y. Global health is local health: a multidisciplinary perspective of COVID-19. Ochsner J. 2020;20(2):123-133. doi: $10.31486 /$ toj.20.0059

30. Sinclair RR, Allen T, Barber L, et al. Occupational health science in the time of COVID-19: now more than ever. Occup Health Sci. 2020;4(1-2):1-22. doi:10.1007/s41542-020-00064-3

31. Lo Bianco G, Di Pietro S, Mazzuca E, et al. Multidisciplinary approach to the diagnosis and in-hospital management of COVID-19 infection: a narrative review. Front Pharmacol. 2020;11:1942. doi:10.3389/fphar.2020.572168

32. NHS. Clinical practice guide for improving the management of adult COVID-19 patients in secondary care, Shared learning from high performing trusts during COVID-19 pandemic; December, 2020. Available from: https://www.gettingitrightfirsttime.co.uk/ wp-content/uploads/2020/12/Covid19-Clinical-Practice-Guidance -S-FINAL.pdf. Accessed July 23, 2021.
33. Galluccio F, Ergonenc T, Martos AG, et al. Treatment algorithm for COVID-19: a multidisciplinary point of view. Clin Rheumatol. 2020;39(7):2077-2084. doi:10.1007/s10067-02005179-0

34. Bragazzi NL, Mansour M, Bonsignore A, Ciliberti R. The role of hospital and community pharmacists in the management of COVID-19: towards an expanded definition of the roles, responsibilities, and duties of the pharmacist. Pharmacy. 2020;8(3):140. doi: $10.3390 /$ pharmacy 8030140

35. Li H, Zheng S, Liu F, Liu W, Zhao R. Fighting against COVID-19: innovative strategies for clinical pharmacists. Res Social Adm Pharm. 2021;17(1):1813-1818. doi:10.1016/j. sapharm.2020.04.003

36. Ali E, Thulasika P, Sarah A, Cindy T. Pharmacists and COVID-19. J. Pharm. Policy Pract. 2020;13(1):36. doi:10.1186/ s40545-020-00241-3

37. Glotta A, Faldarini N, Biggiogero M, et al. Role of physiotherapy team in critically ill COVID-19 patients pronation: can a multidisciplinary management reduce the complications rate? medRxiv. 2021. doi:10.1101/2021.06.20.21258949

38. Mohapatra B, Mohan R. Speech-language pathologists' role in the multi-disciplinary management and rehabilitation of patients with Covid-19. JRM CC. 2020;3:1000037. doi:10.2340/200307111000037

39. Yang M, Dong $\mathrm{H}, \mathrm{Lu} \mathrm{Z}$. Role of anaesthesiologists during the COVID-19 outbreak in China. Br J Anaesth. 2020;124(6):e666e669. doi:10.1016/j.bja.2020.03.022

40. Arabi YM, Azoulay E, Al-Dorzi HM, et al. How the COVID-19 pandemic will change the future of critical care. Intensive Care Med. 2021;1-10. doi:10.1007/s00134-021-06352-y

41. World Health Organization. Maintaining essential health services: operational guidance for the COVID-19 context Interim guidance; June 1, 2020. Available from: https://apps.who.int/iris/handle/ 10665/332240. Accessed July 22, 2021.

42. Poudel A, Lau ETL, Deldot M, Campbell C, Waite NM, Nissen LM. Pharmacist role in vaccination: evidence and challenges Pharmacist role in vaccination: evidence and challenges. Vaccine. 2019;37(40):6-13. doi:10.1016/j. vaccine. 2019.08 .060

43. Singh N, Singh AP, Singh AP. Role of pharmacist towards Covid 19. Curr Opin Infect Dis. 2020;1(6):104-106.

44. Swift MD, Sampathkumar P, Breeher LE, Ting H, Virk A. Mayo clinic's multidisciplinary approach to Covid-19 vaccine allocation and distribution. Innov Care Delivery. 2021;2(1):1-9. doi:10.1056/CAT.20.0696

45. WHO \& UNICEF. COVID-19 vaccination: supply and logistics guidance; 2021a.

46. PATH \& WHO. Integrating the supply chains of vaccines and other health commodities. Immunization Systems and Technologies for Tomorrow; 2013:1-7. Available from: http:// www.path.org/publications/files/TS_opt_integrating_br.pdf. Accessed September 25, 2021.

47. Wada YH, Musa MK, Ekpenyong A, Adebisi YA, Musa MB, Khalid GM. Increasing coverage of vaccination by pharmacists in Nigeria; an urgent need. Public Health Pract. 2021;2:100148. doi:10.1016/j.puhip.2021.100148

48. WHO \& UNICEF. Monitoring COVID-19 vaccination: considerations for the collection and use of vaccination data; 2021b.

49. Elbeddini A, Prabaharan T, Almasalkhi S, Tran C. Pharmacists and COVID-19. J Pharm Policy Pract. 2020;13 (36): $1-4$.

50. Balkhi B, Aljadhey H, Mahmoud MA, et al. Readiness and willingness to provide immunization services: a survey of community pharmacists in Riyadh, Saudi Arabia. Saf Health. 2018;4(1):1-7. doi:10.1186/s40886-018-0068-y 
51. Bach A, Goad J. The role of community pharmacy-based vaccination in the USA: current practice and future directions. Integr Pharm Res Pract. 2015;4:67-77. doi:10.2147/iprp.s63822

52. EHAC. EHAC accreditation. National Environmental Health, Science and Protection Accreditation Council. Available from: https://www.nehspac.org/whyehac/. Accessed July 23, 2021.

53. CDC. 10 essential environmental public health services. Available from: https://www.cdc.gov/nceh/ehs/10-essential-services/index. html. Accessed July 23, 2021.

54. Barba R, Rosado C, Pardo-Moreno J, Rey-Biel J. Managing people, roles, and resources during Covid-19 surge. NEJM Catal Innov Care Deliv. 2020. doi:10.1056/CAT.20. 0152

55. Alam MA. Leading in the shadows: understanding administrative leadership in the context of COVID-19 pandemic management in Bangladesh. IJPL. 2020;17(1):95-107. doi:10.1108/IJPL-06-20200050

56. Dennerlein JT, Burke L, Sabbath EL, et al. An integrative total worker health framework for keeping workers safe and healthy during the COVID-19 pandemic. Hum Factors. 2020;62 (5):689-696. doi:10.1177/0018.7208.20932699

57. Ling L, Wong WT, Wan WTP, Choi G, Joynt GM. Infection control in non-clinical areas during the COVID-19 pandemic. Anaesthesia. 2020;75(7):962-963. doi:10.1111/anae.15075

58. Griffin KM, Karas MG, Ivascu NS, Lief L. Hospital preparedness for COVID-19: a practical guide from a critical care perspective. Am J Respir Crit Care Med. 2020;201(11):1337-1344. doi:10.1164/rccm.202004-1037CP

59. Aliberti S, Amati F, Pappalettera M, et al. COVID-19 multidisciplinary high dependency unit: the Milan model. Respir Res. 2020;21(1):260. doi:10.1186/s12931-020-01516-8

60. Haleeqa MA, Alshamsi I, Al Habib A, et al. Optimizing supportive care in COVID-19 patients: a multidisciplinary approach. J Multidiscip Healthc. 2020;13:877-880. doi:10.2147/JMDH. S264168

61. Hyun J, You S, Sohn S, et al. Psychosocial support during the COVID-19 outbreak in Korea: activities of multidisciplinary mental health professionals. J Korean Med Sci. 2020;35(22): e211. doi:10.3346/jkms.2020.35.e211

62. Lopes N, Vernuccio F, Costantino C, et al. An Italian guidance model for the management of suspected or confirmed COVID-19 patients in the primary care setting. Front Public Health. 2020;8:572042. doi:10.3389/fpubh.2020.572042

63. Parajuli RR, Mishra B, Banstola A, et al. Multidisciplinary approach to COVID-19 risk communication: a framework and tool for individual and regional risk assessment. Sci. Rep. 2020;10 (1):21650. doi:10.1038/s41598-020-78779-0

64. Balkhair A, Al Jufaili M, Al Wahaibi K, et al. "Virtual interdisciplinary COVID-19 team": a hospital pandemic preparedness approach. Oman Med J. 2020;35(6):e190-e190. doi:10.5001/ omj.2020.131

65. Yuan J, Kou S, Liang Y, Zeng J, Pan Y, Liu L. PCR assays turned positive in 25 discharged COVID-19 patients. Clin Infect Dis. 2020;71(16):2230-2232. doi:10.1093/cid/ciaa398

66. Aiash $\mathrm{H}$, Khodor $\mathrm{M}$, Shah J, et al. Integrated multidisciplinary post-COVID-19 care in Egypt. Lancet. 2021;9(7):e908-e909. doi:10.1016/S2214-109X(21)00206-0

67. Wang $\mathrm{D}, \mathrm{Hu} \mathrm{B}, \mathrm{Hu} \mathrm{C}$, et al. Clinical characteristics of 138 hospitalized patients with 2019 novel coronavirus infected pneumonia in Wuhan, China. J Am Med Assoc. 2020;323(11):1061. doi:10.1001/jama.2020.1585

68. Clerkin KJ, Fried JA, Raikhelkar J, et al. COVID-19 and cardiovascular disease. Circulation. 2020;141(20):1648-1655. doi:10.1161/CIRCULATIONAHA.120.046941
69. Baig AM, Khaleeq A, Ali U, Syeda H. Evidence of the COVID-19 virus targeting the CNS: tissue distribution, host-virus interaction, and proposed neurotropic mechanisms. ACS Chem Neurosci. 2020;7:22-59. doi:10.1021/acschemneuro.0c00122

70. Zhao Y, Zhao Z, Wang Y, Zhou Y, Ma Y, Zuo W. Single-cell RNA expression profiling of ACE2, the putative receptor of Wuhan 2019-nCov. bioRxiv. 2020;21:32. doi:10.1101/2020.01.26.919985

71. Xia J, Tong J, Liu M, Shen Y, Guo D. Evaluation of coronavirus in tears and conjunctival secretions of patients with SARS-CoV-2 infection. J. Med. Virol. 2020;92(6):589-594. doi:10.1002/ jmv. 25725

72. Brooks SK, Webster RK, Smith LE, et al. The psychological impact of quarantine and how to reduce it: rapid review of the evidence. Lancet. 2020;395(10227):912. doi:10.2139/ ssrn.3532534

73. Montani D, Savale L, Beurnier A, et al. Multidisciplinary approach for post-acute COVID-19 syndrome: time to break down the walls. Eur Respir J. 2021;58(1):2101090. doi:10.1183/ 13993003.01090-2021

74. Survivor Corps. Post-COVID Care: guidelines for multidisciplinary care centers; March, 2021. Available from: https://static1. squarespace.com/static/5e8b5f63562c031c16e36a93/t/ 605a8a3262f0191b99584df0/1616546355297/PCCC+Standard +of+Practice+3_23.pdf. Accessed July 22, 2021.

75. Ismael J, Losco F, Quildrian S, et al. Multidisciplinary approach to COVID-19 and cancer: consensus from scientific societies in Argentina. ecancer. 2020;14:1044. doi:10.3332/ ecancer.2020.1044

76. Kumar S, Chmura S, Robinson C, et al. Alternative multidisciplinary management options for locally advanced NSCLC during the Coronavirus disease 2019 global pandemic. J Thorac Oncol. 2020;15(7):1137-1146. doi:10.1016/j.jtho.2020.04.016

77. Round T, L'Esperance V, Bayly J, et al. COVID-19 and the multidisciplinary care of patients with lung cancer: an evidence-based review and commentary. $\mathrm{Br}$. J. Cancer. 2021;125(5):629-640. doi:10.1038/s41416-021-01361-6

78. Erturk GA, Sahin A, Bati Ay E, et al. A multidisciplinary approach to Coronavirus disease (COVID-19). Molecules. 2021;26(12):3526. doi:10.3390/molecules 26123526

79. Bashshur RL, Goldberg MA. The origins of telemedicine and e-health. Telemed J E Health. 2014;20(3):190-191. doi:10.1089/ tmj.2014.9996

80. Smith AC, Thomas E, Snoswell CL, et al. Telehealth for global emergencies: implications for coronavirus disease 2019 (COVID-19). J Telemed Telecare. 2020:1357633X20916567. doi:10.1177/1357633X20916567.

81. Greenhalgh T, Koh GCH, Car J. COVID-19: a remote assessment in primary care. $B M J .2020$. doi: $10.1136 / \mathrm{bmj} . \mathrm{m} 1182$

82. Reforma LG, Duffy C, Collier AY, et al. A multidisciplinary telemedicine model for management of coronavirus disease 2019 (COVID-19) in obstetrical patients. Am J Obstet Gynecol. 2020;2(4):100180. doi:10.1016/j.ajogmf.2020.100180

83. World Health Organization. Interim guidance. Critical preparedness, readiness and response actions for COVID-19; June 24, 2020. Available from: http://www.gbchealth.org/reimagining-the-privatesectors-role-in-health-amid-covid-19/. Accessed July 21, 2021.

84. GBCHealth. Reimagining the private sector's role in health amid COVID-19. News on July, 2020. Available from: http://www. gbchealth.org/reimagining-the-private-sectors-role-in-health-amid -covid-19/. Accessed July 21, 2021.

85. WHO \& UNICEF. The role of community health workers in COVID-19 vaccination implementation support guide; April 26, 2021. Available from: https://apps.who.int/iris/bitstream/handle/ 10665/340986/WHO-2019-nCoV-NDVP-CHWs-role-2021.1-eng. pdf. Accessed July 22, 2021. 
86. Neumann PJ, Cohen JT, Kim DD, Ollendorf DA. Consideration of value-based pricing for treatments and vaccines is important, even in the COVID-19 pandemic: study reviews alternative pricing strategies (cost-recovery models, monetary prizes, advanced market commitments) for COVID-19 drugs, vaccines, and diagnostics. Health Aff. 2020;40(1):53-61.

87. Al-Taweel D, Al-Haqan A, Bajis D, et al. Multidisciplinary academic perspectives during the COVID-19 pandemic. Int $J$ Health Plann Manage. 2020;35(6):1295-1301. doi:10.1002/hpm.3032

88. Holmes EA, O'Connor RC, Perry VH, et al. Multidisciplinary research priorities for the COVID-19 pandemic: a call for action for mental health science. Lancet Psychiatry. 2020;7(6):547-560. doi:10.1016/S2215-0366(20)30168-1

89. Golan MS, Trump BD, Cegan JC, Linkov I. The vaccine supply chain: a call for resilience analytics to support COVID-19 vaccine production and distribution. Springer; 2021:389-437. doi:10.1007/978-3-030-71587-8_22

90. Yang XX, Li CM, Huang CZ. Curcumin modified silver nanoparticles for highly efficient inhibition of respiratory syncytial virus infection. Nanoscale. 2016;8(5):3040-3048. doi:10.1039/ C5NR07918G

91. Al-Mandhari A, Kodama C, Abubakar A, Brennan R. Solidarity in response to COVID-19 outbreak in the Eastern Mediterranean region. East Mediterr Health J. 2020;26(5):492-494. doi:10.26719/2020.26.5.492

92. World Health Organization. 2019 novel Coronavirus (2019$\mathrm{nCoV}$ ): strategic preparedness and response plan; 2020.

93. Moat KA, Lavis JN, Clancy SJ, El-Jardali F, Pantoja T. Evidence briefs and deliberative dialogues: perceptions and intentions to act on what was learnt. Bull World Health Organ. 2013;92(1):20-28. doi:10.2471/BLT.12.116806

94. El-Jardali F, Bou-Karroum L, Fadlallah R. Amplifying the role of knowledge translation platforms in the COVID-19 pandemic response. Health Res Pol Syst. 2020;18:1-7.

95. OECD 2020. No policy maker is an island: the international regulatory co-operation response to the COVID-19 crisis; June 8, 2020. Available from: https://www.oecd.org/coronavirus/pol icy-responses/covid-19-and-africa-socio-economic-mplicationsand-policy-responses-96e1b282/. Accessed July 23, 2021.
96. Reeves JJ, Hollandsworth HM, Torriani FJ, et al. Rapid response to COVID-19: health informatics support for outbreak management in an academic health system. $J$ Am Med Inform Assoc. 2020;27(6):853-859. doi:10.1093/jamia/ocaa037

97. Vahidy F, Jones SL, Tano ME, et al. Rapid response to drive COVID-19 research in a learning health care system: rationale and design of the Houston methodist COVID-19 surveillance and outcomes registry (CURATOR). JMIR Med Inform. 2021;9(2): e26773. doi: $10.2196 / 26773$

98. Boyce MR, Katz R. Community health workers and pandemic preparedness: current and prospective roles. Front Public Health. 2019;7:62. doi:10.3389/fpubh.2019.00062

99. Tanne JH, Hayasaki E, Zastrow M, Pulla P, Smith P, Rada AG. Covid-19: how doctors and healthcare systems are tackling coronavirus worldwide. BMJ. 2020;368:m1090. doi:10.1136/bmj. $\mathrm{m} 1090$

100. Bajwa SJ, Mehdiratta L. Preparedness for emergencies and complications: proactive planning and multidisciplinary approaches. Indian J Anaesth. 2020;64(5):366. doi:10.4103/ija.IJA 43420

101. Liu C, Zhou Q, Li Y, et al. Research and development on therapeutic agents and vaccines for COVID-19 and related human coronavirus diseases. ACS Cent Sci. 2020;6(3):315-331. doi:10.1021/acscentsci.0c00272

102. Moradian N, Ochs HD, Sedikies C, et al. The urgent need for integrated science to fight COVID-19 pandemic and beyond. J Transl Med. 2020;18(1):1-7. doi:10.1186/s12967-020-02364-2

103. Li G, Fan Y, Lai Y, et al. Coronavirus infections and immune responses. J Med Virol. 2020;92(4):424-432. doi:10.1002/ jmv. 25685

104. Aderem A, Adkins JN, Ansong C, et al. A systems biology approach to infectious disease research: innovating the pathogen-host research paradigm. MBio. 2011;2(1):e00325-10. doi:10.1128/mBio.00325-10
Journal of Multidisciplinary Healthcare

\section{Publish your work in this journal}

The Journal of Multidisciplinary Healthcare is an international, peerreviewed open-access journal that aims to represent and publish research in healthcare areas delivered by practitioners of different disciplines. This includes studies and reviews conducted by multidisciplinary teams as well as research which evaluates the results or conduct of such teams or healthcare processes in general. The journal

\section{Dovepress}

covers a very wide range of areas and welcomes submissions from practitioners at all levels, from all over the world. The manuscript management system is completely online and includes a very quick and fair peer-review system. Visit http://www.dovepress.com/testimonials. php to read real quotes from published authors. 